\title{
Fraseología y lexicografía: análisis y propuestas
}

\author{
M. ${ }^{a}$ Isabel González Aguiar \\ Universidad de La Laguna
}

\section{INTRODUCCIÓN}

En los últimos tiempos, se ha llamado la atención sobre la necesidad de abordar las cuestiones espinosas que se plantean en la redacción de los diccionarios de fraseología, con el fin de proponer soluciones viables ante tales dificultades. Esta preocupación ha originado que, desde hace ya varias décadas, países como la Unión Soviética hayan desarrollado una nueva rama de la lexicografía, la fraseografía, cuyo objetivo es examinar "los problemas teóricos y prácticos que plantea la confección de diccionarios fraseológicos" (Tristá Pérez 1998: 297). En España, esta línea de investigación apenas ha sido cultivada, de ahí que se eche en falta la publicación "de trabajos hechos en español y sobre el español y que traten fenómenos complejos, heterogéneos y bastante frecuentes" (Wotjak 1998: 7).

El objeto de este artículo es exponer y reflexionar sobre las cuestiones implicadas en el análisis lexicográfico de las unidades fraseológicas (UFS) ${ }^{1}$. Para ello, nos centraremos en el examen que el diccionario académico les concede en su última edición (2001) y compararemos su metodología con la que utilizan otras obras lexicográficas generales como el DUE-98 y el DFEM. Pretendemos así demostrar la necesidad

1 El empleo general de esta denominación para las unidades que estudia la fraseología ha sido acogido por autores como Wotjak 1998 o Corpas 1997. Sin embargo, no es un tecnicismo compartido por todos los estudiosos que incluso catalogan de "abusivo" el empleo extensivo de la misma (Porto Dapena 2002: 152). 
de realizar estudios fraseográficos que permitan establecer principios aplicables en cualquier descripción de fraseología ${ }^{2}$. En este empeño, contamos con la experiencia de haber trabajado en colaboración con el Dr. Ortega Ojeda en la redacción del Diccionario de expresiones y refranes del español de Canarias (2000), por lo que muchos de los problemas que vamos a exponer los hemos tenido que afrontar y, de alguna manera, resolver (Ortega Ojeda y González Aguiar 2001).

Como es sabido, la competencia léxica de los hablantes de una comunidad no sólo está formada por palabras combinadas libremente según las reglas gramaticales correspondientes, sino que hay además un amplio conjunto de voces complejas, formadas por trozos de discurso previamente elaborados cuya composición está fijada ${ }^{3}$. De la existencia de estas últimas unidades nos ha dado cuenta la lexicografía española desde el s. XVIII, en repertorios tan célebres como el de Correas o en el Diccionario de Autoridades. Sin embargo, a pesar de que esta parcela del vocabulario no ha sido despreciada en los registros lexicográficos, hasta hace bien poco no se han iniciado líneas de investigación que profundicen en el estudio de las UFS, ni se ha desarrollado una teoría fraseográfica, paralela a la que hasta el momento se ha aplicado a las unidades simples ${ }^{4}$.

Ante estas carencias, es imprescindible la elaboración de unos principios que guíen y sistematicen los procedimientos y los recursos fraseográficos, principios que, a su vez, sean flexibles y se puedan adaptar a las necesidades concretas de cada repertorio ${ }^{5}$. A las deficiencias

2 Otros trabajos que se han planteado objetivos similares a los de este artículo son: Ruiz Gurillo 2000, Castillo Carballo 2000 y Déniz Hernández 2000.

3 Es lo que Coseriu (1964) distinguió como técnica del discurso o del hablar y discurso repetido o lenguaje ya hablado.

4 La excepción la encontramos en los estudios lingüísticos soviéticos, en los que este desarrollo comenzó desde mediados del siglo pasado. En Haensch et al. (1982: 250), Ettinger se refiere a la nutrida producción de bibliografía soviética sobre este tema.

5 Para Wotjak (1998) todo registro lexicográfico que se ocupe de la descripción de las UFS debe establecer de entrada los rasgos singulares que lo definen y, consecuentemente, debe ser coherente con esas particularidades. Los rasgos específicos afecta- 
apuntadas se suma el que los manuales generales de lexicografía no dispongan de apartados especiales para las cuestiones relacionadas con el tratamiento de las UFS, y que, cuando los tengan, apenas analicen aspectos muy concretos. Es el caso de Ettinger, que dedica un capítulo a la formación de palabras y a la fraseografía en el manual de Haensch et al. (1982: 233-258). En ese capítulo, sin adentrarse en otras cuestiones, plantea los problemas macroestructurales que surgen a la hora de determinar qué tipo de fraseologismos se han de recopilar. También realiza un examen insatisfactorio Martínez de Sousa (1996), que, aunque emplea treinta páginas (pp. 73-103) para explicar el concepto de definición (y derivados), sólo registra el lema definición de locuciones con la breve indicación que sigue: "Siempre que sea posible, las locuciones deben definirse mediante un segmento de frase que en un contexto determinado actúe de sinónimo" (p. 81). Un último ejemplo lo encontramos en Porto Dapena (2002: 148-170), que al igual que Ettinger, si bien con mayor profundidad y extensión, desglosa las cuestiones macroestructurales cardinales relativas a la selección y clasificación de las expresiones fijas a partir de la aceptación de la clasificación expuesta en Casares (una catalogación de tipo léxico-gramatical). De nuevo se echa en falta información sobre qué pautas se pueden aplicar en la definición de las UFS.

\section{LA FRASEOLOGÍA QUE REGISTRA EL DRAE-2001}

El Diccionario académico se define como "un diccionario general de lengua", a lo que añade que "no puede registrar todo el léxico del español" (DRAE-2001: XXXIII). Esta última precisión justifica que sólo se incorpore "una representación de los usos más extendidos o característicos" de aspectos como "los dialectalismos españoles, americanos y filipinos, tecnicismos, vulgarismos y coloquialismos, arcaís-

rían a: los fines que pretende tener (codificadores / decodificadores), el tipo de usuario al que va dirigido (hablante como lengua materna o no, escolar o general, etc.), a la vigencia de las unidades, a la zona del dominio hispánico que se vaya a describir, al tipo de información que vaya a proporcionar en la definición, etc. 
mos, etc.”. En lo que se refiere a la fraseología, el DRAE registra las estructuras compuestas (formas complejas es la etiqueta que emplea) al final del artículo lexicográfico de cada entrada. Dentro del bloque "formas complejas", diferencia:

a) Las combinaciones estables del lema (de un sustantivo) con otros elementos que desempeñen una función adjetiva con respecto a él.

b) Las locuciones, expresiones, frases ${ }^{6}$ e interjecciones.

Nuestro análisis se ocupará únicamente de las unidades del segundo bloque, partiendo del concepto de fraseología que proporciona el propio diccionario académico en el artículo lexicográfico correspondiente, en cuya definición llama la atención la falta de coincidencia con la terminología empleada para referirse a las combinaciones que aglutina ${ }^{7}$ :

DRAE-2001: fraseología. [...] 4. Conjunto de frases hechas, locuciones figuradas, metáforas y comparaciones fijadas, modismos y refranes, existentes en una lengua, en el uso individual o en el de algún grupo. || 5. Parte de la lingüística que estudia las frases, los refranes, los modismos, los proverbios y otras unidades de sintaxis total o parcialmente fijas ${ }^{8}$.

De entrada, un requisito fundamental en todo diccionario es que éste sea riguroso y sistemático en las elecciones macro y microestructurales que realiza'. En el caso de una obra lexicográfica de fraseología,

6 Se incluyen como tales las combinaciones VERBO + PRONOMBRE, gastarlas o gastárselas, pirarse o pirárselas, diñarla, etc.

7 Martínez de Sousa (1995) registra fraseografía como 'Tratado en que se recogen y estudian las frases, locuciones, modismos, refranes, etc., de una lengua'. En el término fraseología, aparte de las acepciones $1 .^{\mathrm{a}}$ y $4 .^{\mathrm{a}}$ que registra el $D R A E$, añade otras dos: 'Parte del artículo lexicográfico en que se agrupan y se definen las frases formadas en torno a la voz entrada' y 'Manera peculiar y característica en que un individuo, un grupo o un idioma construye y ordena las frases'.

8 Los subrayados son nuestros. La quinta acepción ha sido introducida en esta última edición, y de ella destacamos que engloba como objeto de estudio las UFS cuya sintaxis puede no estar totalmente fijada, incluyendo así las colocaciones.

9 A pesar de las mejoras alcanzadas en el repertorio académico, queda mucha fraseología sin incluir. Quizá, por la desbordante creación de fraseologismos se debería op- 
la primera dificultad es la delimitación de las unidades que va a registrar, por lo que el concepto de fraseología debe ser precisado en el Prólogo correspondiente. Aunque el DRAE no aclara en las Advertencias qué concepción de fraseología adopta ${ }^{10}$, por la marcación de que se vale sabemos que acoge lo que denomina locuciones, expresiones y frases. Como en ningún apartado se explican las diferencias que se establecen entre cada uno de estos términos, hemos de deducir de su empleo el valor que concede a estas etiquetas ${ }^{11}$. Examinado este, llegamos a la conclusión de que es una distinción que se aplica según la

tar por la gestación de un diccionario de fraseología paralelo al diccionario de voces simples, o en todo caso, como consideramos que la inclusión de las UFS en los diccionarios generales de lengua debe mantenerse, por la aplicación de criterios de selección constantes y homogénos.

Uno de los efectos de no realizar un registro satisfactorio se revela en las obras de lexicografía regional que usan el método contrastivo para escoger las UFS que describen. Así, por las limitaciones del repertorio general, el Diccionario de expresiones y refranes del español de Canarias registra fraseologismos que, si bien no aparecen en la obra académica, sí están recopilados en otras, como es el caso de los ejemplos que citamos a continuación y que han sido descritos por Hormigos García (1998) para el habla de Madrid: apúntalo en el libro verde, como Mateo con su guitarra, con el tiempo y una caña, con más mierda que el palo de un gallinero, jcomo Dios pintó a Perico!, más antiguo que mear de pie, no doblar el espinazo, etc.

10 Tristá Pérez (1998: 300) distingue una concepción estrecha de fraseografía de otra más amplia: la primera se limitaría sólo a las combinaciones fijas de palabras equivalentes por su estructura a un sintagma, mientras que la segunda abarcaría las combinaciones fijas con estructura sintagmática u oracional. Esta distinción la toma de la escuela soviética.

11 De estos términos, el DRAE-2001 presenta las siguientes definiciones, las cuales tampoco aclaran taxativamente los usos terminológicos:

frase. [...] 7. Ling. Expresión acuñada constituida generalmente por dos o más palabras cuyo significado conjunto no se deduce de los elementos que la componen [incluye además frase hecha y frase proverbial].

expresión. [...] 8. Ling. En algunas corrientes de la fraseología, combinación lexicalizada de palabras que no permite variación morfológica.

locución. [...] 4. Gram. Combinación fija de varios vocablos que funciona como una determinada clase de palabras [incluye locución adjetiva, adverbial, conjuntiva, cuantificadora o intensificadora, interjectiva, preposicional o prepositiva, pronominal, sustantiva y verbal]. 
función gramatical de cada construcción y según el nivel de independencia sintagmática u oracional:

- frase se corresponde con locuciones verbales o sintagmas verbales dependientes.

- locución se refiere a sintagmas con cualquier función también dependientes, salvo los verbales.

- expresión hace mención a los enunciados autónomos o sintácticamente independientes.

Con el uso de esta terminología se han corregido los errores que se cometían en las anteriores ediciones del DRAE, en las que no se seguía un criterio firme al adjudicar la marcación fraseológica. Al cotejar las marcas empleadas en la anterior edición con las actuales, comprobamos la unificación terminológica que se ha aplicado:

$D R A E$-1992: largo como pelo de huevo, o de rata. loc. fig. y fam. Tacaño, miserable.

DRAE-2001: largo como pelo de huevo, o de rata. locs. adjs. coloqs. Tacaño, miserable.

$D R A E-1992$ : más viejo que la sarna. expr. fig. y fam. Muy viejo o antiguo.

$D R A E-2001$ : más viejo que la sarna. loc. adj. coloq. Muy viejo o antiguo.

$D R A E-1992:$ más sordo que una tapia. fr. fig. y fam. Muy sordo.

$D R A E-2001$ : más sordo que una tapia. loc. adj. coloq. Muy sordo.

De las unidades mencionadas por el $D R A E$ en la definición de fraseología (frases hechas, locuciones figuradas, metáforas y comparaciones fijadas, modismos y refranes), el diccionario académico ha excluido los refranes desde la edición de 1970. Lo mismo ha pasado en esta última edición con las frases proverbiales que aún permanecían en él ${ }^{12}$. Esta exclusión se ha debido a lo próximas que están muchas

12 Si bien las descripciones lexicográficas han separado los refranes del resto de UFS, hay opiniones encontradas sobre cómo se debe abordar el análisis: algunos autores consideran que la paremiología y la fraseología deben ser analizadas como disciplinas diferentes (Casares 1950; Wotjak 1998), mientras que otros estiman que las pare- 
del molde característico del refrán, bien por su estructura formal, bien por su contenido moral ${ }^{13}$. Así ha sucedido con las siguientes frases que el DRAE-1992 incluía como proverbiales, pero que ya han desaparecido: sarna con gusto no pica, en buenas manos está el pandero, más vale malo conocido que bueno por conocer, etc. No obstante, permanecen enunciados fraseológicos del tipo a menos bulto, más claridad, no todo el monte es orégano, ignorancia no quita pecado, lo barato es caro, etc., que contienen el valor de sentencia propio de los refranes y que son un claro exponente de la dificultad de establecer límites dentro de lo fraseológico (Porto Dapena 2002: 170).

Del resto de voces incluidas, extraña la incorporación de interjecciones compuestas por una sola palabra en el espacio destinado a la fraseología, si bien comparten con las UFS fijación formal y pragmática. Estos sintagmas, al estar compuestos por una unidad gráfica no encajan dentro de las formas complejas que, tal y como el adjetivo complejo indica, son combinaciones de dos o más palabras, resultando así que su inclusión entra en contradicción con una de las características esenciales de las unidades fraseológicas, que es su estructura compleja (Tristá Pérez 1998: 300). Es el caso de:

cómo. interj. U. para denotar extrañeza o enfado.

Por la misma razón, tampoco casan con esta concepción las formas verbales fijadas que aparecen incluidas alfabéticamente en los listados de formas complejas. Por ejemplo, bajo decir aparecen expresiones univerbales como:

digamos. expr. coloq. por decirlo así. $\|$ digo. interj. U. para expresar sorpresa, asombro, etc. $\| 2$. ya lo creo. [...] $\|$ dime. interj. coloq. $\mathrm{Cu}$ $b a$. U. como saludo entre personas entre las que media confianza.

Ante estas inclusiones, parece que el DRAE estima la fijación como el criterio determinante para catalogar estas unidades dentro del grupo de formas complejas (que debería tener una etiqueta más ajustada a es-

mias, aunque son las "parientes pobres" en los estudios de fraseología, deben ser incluidas en estos (Zuluaga 1980; Corpas Pastor 1998).

13 En Porto Dapena (2002: 168) se aclara el significado de frase proverbial. 
te concepto, algo así como formas fijadas). A pesar de ello, en las $A d$ vertencias apuesta por la idiomaticidad como requisito fundamental para la inclusión de una voz en el listado de formas complejas:

Además de registrar las entradas constituidas por una sola palabra ( $\mathrm{p}$. ej., perla, aceite, susto), el Diccionario recoge series de palabras que, combinadas de una determinada manera, expresan conceptos no interpretables mediante la simple adición de los significados de sus componentes (de perlas, aceite virgen, no ganar para sustos) (p. XL).

De forma coherente con el criterio que manifiesta la Academia, se entiende la no inclusión de muchas UFS en el diccionario por ser su sentido interpretable mediante la adición de los significados de sus componentes. Es el caso de las colocaciones, en las que, tal y como expone Ruiz Gurillo (2001: 263), no es frecuente la idiomaticidad, si bien hay mayor o menor grado de fijación.

Por otra parte, no se entiende que se registren unidades que, según nuestra valoración, pertenecen a la técnica del discurso. En los siguientes casos quedan ilustradas algunas de las situaciones a las que nos referimos:

a) Una estructura problemática es la construcción con el verbo SER + SUSTANTIVO (determinado este último por el artículo indefinido). Si un uso como ser alguien un bestia se lematiza como acepción de bestia, cuya cuarta acepción es 'persona ruda e ignorante', ¿por qué no se actúa de la misma manera en todas las ocasiones? Para Tristá Pérez (1998: 301), es la frecuencia de uso el argumento que lleva a considerar estas construcciones como fraseológicas. Ejemplos de este modelo son:

ser una maravilla. fr. Ser singular y excelente ${ }^{14}$.

ser alguien una ardilla. fr. coloq. Ser vivo, inteligente y astuto.

ser alguien un manitas. fr. coloq. Tener gran habilidad para una actividad o un oficio.

b) También es cuestionable la inclusión de algunos lemas que, en ocasiones, carecen de idiomaticidad y en los que el esquema sintáctico

14 La primera acepción de maravilla es 'suceso o cosa extraordinarios que causan admiración'. 
más común es VERBO + SUSTANTIVO. En esta ocasión su significado es deducible de la suma de componentes, por lo que pueden ser concebidos como construcciones propias de la técnica del discurso, o también como construcciones frecuentes pero no totalmente fijadas, es decir, como colocaciones:

coger, o tomar, una curva un vehículo o su conductor. frs. Pasar de un tramo recto de camino o carretera a un tramo curvo.

COMENTARIO: ¿También sería un fraseologismo coger un bache?

tener barriga. fr. Tener por gordura el abdomen abultado.

COMENTARIO: Si aceptamos que barriga. [...] \| 5. coloq. Región exterior del cuerpo humano, especialmente si es abultado. ¿Existirá también fijación en tener canas o en tener joroba?

tener alguien barra. [...] || 2. Chile. Ser popular. Juanito tiene mucha barra entre las jovencitas.

COMENTARIO: El DRAE registra barra. [...] $\|$ 19. Am. hinchada (\| multitud de hinchas). ¿Es un fraseologismo o un uso de la técnica del discurso?

Entre las formas complejas, el DRAE registra UFS regionales, en concreto de los diferentes países hispanoamericanos. Esto significa que no se tiene como objetivo reflejar la fraseología regional del español de España, aunque de forma muy esporádica se incluye alguna que otra UF de regiones españolas, e incluso de localidades, como:

dar, echar, o hacer, barzones. frs. And. y Ext. Dar paseos ociosos. sentar las botas. fr. En Jerez de la Frontera, localidad española de la provincia de Cádiz, colocarlas en hileras a lo largo de las paredes de las bodegas.

a caliche. loc. adv. And. Dicho de beber: a chorro.

bailar en una pata. fr. coloq. Can. y Am. Estar muy contento ${ }^{15}$.

Por otra parte, se listan tecnicismos fraseológicos, sobre todo provenientes del lenguaje del Derecho (aunque también son abundantes los relativos a la Marina y a ciertos deportes). Los diccionarios de fraseología como el DFEM no incluyen regularmente tecnicismos como:

15 El lema correcto de esta expresión en Canarias es bailar alguien en una pata sola. 
fulminar el proceso. fr. Der. Hacerlo y sustanciarlo hasta ponerlo en estado de sentencia. || vestir el proceso. fr. Der. Formarlo con todas las diligencias y solemnidades requeridas por derecho.

Lo que sí registran de manera regular son las UFS procedentes de lenguajes técnicos cuyo ámbito de uso se ha extendido mucho más allá de su valor específico originario, como chupar ruedas, estar hasta los topes, cortarse la coleta, irse a pique, echar / lanzar balones fue$r a$, etc. En algunas ocasiones se documenta tanto el uso técnico como el extensivo:

chupar rueda. expr. coloq. En ciclismo, colocarse un corredor inmediatamente después de otro para utilizarlo como pantalla frente a la resistencia del aire. || 2. Copiar, aprovecharse del trabajo del otro.

Además, en el DRAE-2001 hay una concepción que apuesta por ampliar la descripción sin prejuicios que mermen el objetivo documental del diccionario. Esta mejora se manifiesta en el análisis que se le dispensa a una parcela de la competencia fraseológica, la de las UFS malsonantes ${ }^{16}$ y la de las vulgares ${ }^{17}$. De este modo, se le da entrada a un amplio número de UFS que no habían aparecido en los registros anteriores por pudoris causa. Sirva como ilustración el tratamiento de la fraseología inventariada bajo la entrada culo, que ha pasado de tener cuatro lexías complejas y cinco fraseologismos en la edición de 1992, a seis lexías complejas y 16 fraseologismos, casi todos acompañados por las abreviaturas que indican su carácter vulgar y malsonante (vulg. y malson.). No obstante, se sigue prescindiendo de muchas UFS, hecho que se constata en una entrada como cojón, que no presenta en el $D R A E$ ninguna expresión compleja, mientras que el $D F E M$ reúne bajo esta palabra un total de veintitrés.

16 Según el DRAE-2001, los 'que ofenden los oídos de personas piadosas o de buen gusto' (s.v. malsonante).

17 En el DRAE-2001, dicho de lo 'que es impropio de personas cultas o educadas' (s.v. vulgar). 


\section{OTROS RASGOS MACROESTRUCTURALES (PRIMER ENUNCIADO)}

\subsection{ORDEN DE LOS FRASEOLOGISMOS}

Como norma general, en la ordenación de las expresiones el DRAE adopta el criterio de palabras clave, aunque no siempre bien aplicado. Hay algún que otro despiste en la aplicación de este sistema, como los que a continuación se detallan, que se deberían corregir:

Bajo sobar: sobar el lomo. fr. coloq. Arg. y Bol. Adular, halagar a alguien para obtener de él alguna ventaja.

Bajo lomo: sobar el lomo. fr. Dar coba.

Bajo cabeza: ponérsele a alguien en la cabeza algo. fr. metérsele en la cabeza.

metérsele a alguien en la cabeza algo. fr. Figurárselo con poco o ningún fundamento y obstinarse en considerarlo cierto o probable. $\|$ 2. coloq. Perseverar en un propósito o capricho.

Bajo poner. ponérsele a alguien algo en la cabeza. fr. Tener por cierto que sucederá lo pensado o imaginado. Se me puso en la cabeza que vendría. || 2. Empeñarse en algo.

Una de las desventajas de este método de ordenación es la multiplicación de formas complejas en el caso de las expresiones en las que la primera palabra adopta diversas variantes léxicas, con el consiguiente incremento del cuerpo del diccionario (Ruiz Gurillo 2001: 263-264).

\subsection{LEMATIZACIÓN}

Junto con la redacción de las definiciones, la lematización de las UFS es una de las cuestiones más intrincadas de la labor fraseográfica. Son numerosos los problemas que se plantean en torno al proceso de fijar el enunciado del fraseologismo: bajo qué forma o formas lematizar la unidad, cómo registrar las variantes, cómo indicar la información de contorno ${ }^{18}$...

18 Este es uno de los aspectos pendientes que en este artículo no analizaremos por falta de espacio. A la necesidad de distinguir la información de contorno del resto de información se refieren Martínez 1991 y Castillo 2000. 
En el DRAE, la lematización de las UFS no se lleva a cabo siguiendo un criterio único, aunque sería deseable que se unificara. En general, se fluctúa entre registrar la expresión tantas veces como formas adopte (y remitir entonces de una a otra, colocando la definición bajo la forma que menos restricciones presente), y lematizar en una sola llamada las distintas variantes de la unidad (opción que se representa mediante comas). Veamos un ejemplo de cada caso:

\section{estar a las duras y a las maduras, o ir, o tomar, las duras con, o por, las maduras. frs. coloqs. U. para significar que quien goza de los privilegios de una situación debe cargar asimismo con sus venta- jas.}

apearse alguien del burro. fr. coloq. Reconocer que ha errado en algo.[...] || bajarse alguien del burro. fr. coloq. apearse del burro. || [...] $\|$ caer, o caerse alguien del burro, o de su burro. fr. coloq. Reconocer que ha errado en algo.

Por otra parte, es frecuente la multiplicación, a nuestro juicio innecesaria, de las UFS inventariadas, sobre todo en el caso de las locuciones adverbiales. Esta circunstancia se produce en especial cuando la locución adverbial establece solidaridad con algunos verbos, sin que ello amplíe o reduzca su contenido. Lo que sí es cierto es que hay elementos facultativos que no siempre son fáciles de establecer, sobre todo en los llamados verbos de "predicación incompleta" como estar, quedarse, ponerse, etc. Examinaremos algunos ejemplos tomados del $D R A E-2001$ para compararlos con el análisis que proporcionan el DUE-1998 y el DFEM:

DRAE-2001: de vicio. loc. adv. Sin necesidad, motivo o causa, o como por costumbre. $\|[\ldots]\|$ hablar de vicio alguien. fr. coloq. Ser hablador. $\|[. .]$.$\| quejarse de vicio alguien. fr. coloq. Sentir o dolerse$ por pequeño motivo.

DUE-1998: DE VICIO. 1 (con "quejarse" o verbo equivalente) Sin motivo. $\Rightarrow$ *Injustificado. 2 (inf.) Muy *bueno o muy bien.

DFEM: quejarse u.p. de vicio (inf.). Quejarse sin causa justificada: "Siempre está diciendo que gana muy poco, pero yo creo que se queja de vicio, pues su sueldo es el doble del sueldo promedio".

DRAE-2001: andar de capa caída. fr. coloq. Padecer gran decadencia en bienes, fortuna o salud.|| [...] || ir de capa caída. fr. coloq. an- 


\section{dar de capa caída.}

DUE-1998: DE CAPA CAÍDA (“Andar, Estar, Ir”) *Decayendo de categoría, fortuna, posición, salud, etc. $\odot$ Perdiendo fuerza o intensidad.

DFEM: [andar/estar/ir u.p./u.c.] de capa caída (inf.). [Estar] cada vez peor [física o moralmente]: "El pobre hombre va de capa caída: han tenido que operarle ya por tercera vez".

También, en otras ocasiones se lematiza una UF sin contemplar los enunciados que, según la situación discursiva, puede adoptar. En estos casos este proceso se efectuaría de manera correcta si se dispusiera de una base de datos con los usos oportunos que muestren las diferentes variaciones.

$D R A E-2001$ : y pare usted de contar. expr. U. para poner fin a una narración o enumeración.

DUE-1998: Y PARA [o PARE USTED] DE CONTAR (inf.) Expresión con que se pone fin a una enumeración muy corta, dando a entender que ya no se puede añadir nada ni nadie más.

DFEM: ... y par[a/-e Vd.] de contar (inf.) [Expresión con que se finaliza una enumeración generalmente muy corta]: "No es tan rico como tú crees; tiene un piso en el centro, una casita en la sierra y para de contar".

COMENTARIO: Aparte de la precisión de la marcación y de la definición del DUE-1998 y del DFEM, no se lematizan las dos posibles formas que toma la frase según sea la relación entre el hablante y el oyente.

DRAE-2001: lo que es bueno. loc. sust. m. coloq. Situación más o menos adversa a la que alguien ha de enfrentarse. Cuando tengas que madrugar ya verás lo que es bueno. Se va a enterar de lo que es bueno.

COMENTARIO: La estructura de las oraciones en las que se emplea es ver/saber/enterarse alguien (de) lo que es bueno, y en ellas el verbo siempre aparece en un tiempo que indica una acción por realizar y, desde el punto de vista pragmático, actúa como una advertencia. Todos estos datos no están expresados en el artículo lexicográfico del DRAE-2001. El DUE-1998 y el DFEM no la registran. 


\subsection{MARCACIÓN}

a) Nivel de lengua o registros de habla ${ }^{19}$.

En la nueva edición se ha tenido el acierto de eliminar como sistemática la marca fig. (figurado) y sustituir la marca del registro de habla fam. (familiar) por coloq. (coloquial). Dentro de los fraseologismos, se distinguen los que pertenecen al nivel culto (sin marcación sobre el registro de habla) de los que son propios del nivel vulgar (con la marca vulg. ${ }^{20}$. Sobre estas marcas, hay que comentar que la adjudicación del rasgo coloquial no se hace de forma metódica, pues en algunas expresiones no se señala su pertenencia al nivel informal de habla:

enviar a alguien a buscar berros. fr. Despedirlo, hacer que se vaya. ¡y qué sé yo! expr. Y muchos más, y muchas más cosas. U. para no proseguir una enumeración.

Además, si analizamos otros ejemplos y cotejamos el tratamiento que dispensan a este asunto los principales diccionarios que registran fraseologismos, comprobaremos que no hay acuerdo en la consideración de las expresiones que pueden pertenecer a un nivel o estilo de habla determinado. En el siguiente ejemplo, el diccionario académico le atribuye carácter informal al fraseologismo y lo lematiza de modo diferente a como lo hacen el DUE y el DFEM:

$D R A E-2001:$ tomar cartas en algún negocio. fr. coloq. Intervenir en él. $D U E-1998$ : tomar cartas en el asunto. Intervenir en el asunto de que se trata alguien que tiene autoridad.

DFEM: tomar u.p. cartas en el asunto (f.). Intervenir con autoridad: "Viendo que cada vez se producían más robos en aquel distrito, el gobernador se decidió a tomar cartas en el asunto y envió una patrulla de policías".

19 Son poco frecuentes los fraseologismos marcados como eufemísticos (p. ej. volar al cielo) o los jergales (p. ej. tener onda con alguien, para Argentina). Sobre la intención del hablante, es más habitual encontrar expresiones con las marcas que indican su uso irónico (p. ej. ir, o estar, aviado / apañado).

20 En el caso de los fraseologismos con marcación regional, éstos pertenecen mayoritariamente al estilo coloquial. 


\section{b) Marcación geográfica.}

Sobre las marcas geográficas, destacaremos el empleo de la marca geográfica $E s p$., que identifica a las unidades cuyo ámbito de uso se reduce a España:

estar algo en el bote. fr. coloq. Esp. Ser considerado como ya ganado. $\|$ tener algo en el bote. fr. coloq. Esp. Ser considerado como ya ganado.

tener más cuento que Calleja. fr. coloq. Esp. Ser quejicoso o fantasioso, falsear la realidad, exagerando lo que afecta particularmente.

Aunque en esta edición se ha mejorado la marcación, queda una labor importante: revisar las marcas cronológicas y geográficas, junto con las temáticas. Al final de la Presentación, se indica que es necesario esta tarea ya que "la ausencia de marcas cronológicas o geográficas en muchas de ellas no quiere decir, forzosamente, que se trata de significados vigentes en la actualidad y en todo el ámbito territorial del estado". Sería éste el caso de unidades como ser más agarrado que un chotis 'ser muy tacaño' que aparece sin ningún tipo de marcación en el $D R A E$, cuando se emplea sólo en algunas zonas de España.

c) Marcación cronológica (p. us., desus. y ant.).

En esta edición se ha aliviado el corpus del diccionario con la exclusión de una buena parte de las UFS sin vigencia actual. Otros se mantienen en el "Diccionario de la Lengua Española por no haberse terminado el Diccionario histórico". En la Presentación se señala que la consulta del Banco de datos del español ha permitido "suprimir del Diccionario muchos registros innecesarios, que ya sólo servían de incómodo lastre" (p. XXVIII). En algunos casos, la información sobre la vigencia de las unidades se revela en la forma conjugada del verbo dentro de la definición:

real, real, real por el rey don... y el nombre del rey aclamado. loc. interj. Grito que daban los heraldos y reyes de armas en el momento de la proclamación de un monarca en Castilla.

agua va. expr. Era u. para avisar cuando desde alguna casa iban a echar a la calle agua o inmundicia. $\|$ 2. Era u. para anunciar alguna expresión impropia. 


\section{SOBRE LA DEFINICIÓN LEXICOGRÁFICA (SEGUNDO ENUNCIADO)}

Tal y como ya ha sido señalado por diferentes lexicógrafos (ReyDebove 1971; Bosque 1982; Corrales Zumbado 1990; Mederos 1994), la elaboración de las definiciones es el problema central en la redacción de un diccionario, a la vez que constituye la tarea lexicográfica más original y comprometida. El componente creativo de las definiciones está en cierta manera limitado por la existencia de modelos formales que pretenden abarcar los diferentes modos de significar de cada categoría gramatical.

Antes de analizar la aplicación de estos modelos en la descripción de la fraseología del español, no está de más recordar que los matices de sentido que materializan las UFS son en algunas ocasiones tan variados y sutiles que su formulación no siempre es tarea sencilla. En el mayor o menor grado de opacidad semántica pueden influir los siguientes factores:

- el funcionamiento en bloque de la expresión.

- el carácter idiomático: es un rasgo potestativo que implica un mayor alejamiento del valor de las unidades que lo componen ${ }^{21}$.

- la independencia de la UF: no es lo mismo definir una frase autónoma, que constituya por sí misma un enunciado con sentido completo, que un sintagma que dependa del contexto.

- los valores discursivos que adquieren: para algunas UFS hay que proporcionar datos sobre cuándo, cómo y para qué se usan. En estos casos, en lugar de definir su sentido se explica su empleo.

21 Ocasionalmente, aparece junto al lema y entre paréntesis una aclaración enciclopédica sobre la motivación metafórica de la expresión. Estos datos no se aportan de manera sistemática y son esporádicos:

retozarle a alguien el alcacer. (Por alus. a las bestias, que suelen retozar cuando se hartan de verde). fr. coloq. Estar alegre en demasía.

venir el cuervo. (Por alus. al que alimentaba a San Pablo el ermitaño). fr. coloq. Recibir algún socorro, particularmente si es repetido.

beber alguien como una topinera. (Por alus. al agua de riego que absorben las topineras). fr. Beber mucho. 
Sobre las definiciones que presenta el $D R A E-2001$, dice la Academia en la Presentación que ha trabajado "sin poner en tela de juicio el contenido de las definiciones", a pesar de la sospecha de que muchas "no se corresponden con la realidad actual". Por ello, uno de los objetivos que se espera culminar próximamente es la revisión del contenido de las definiciones a partir del Banco de datos del español (del CREA y del CORDE).

De acuerdo con lo que se expresa en las Advertencias del DRAE-2001, "entre los muchos tipos de texto definitorio", destacan tres modelos:

1. La definición perifrástica.

2. La definición sinonímica.

3. La definición impropia o explicativa ${ }^{22}$.

A continuación, haremos algunas indicaciones sobre cada uno de estos modelos:

1. En el caso de las definiciones perifrásticas, éstas suelen comenzar por una palabra abarcadora que luego se va precisando en el cuerpo de la definición. Así, engañar sería el género próximo o hiperónimo en la expresión dar gato por liebre:

$D R A E-2001:$ dar gato por liebre. fr. coloq. Engañar en la calidad de algo por medio de otra cosa inferior que se le asemeje.

DUE-1998: DAR GATO POR LIEBRE. * Engañar haciendo pasar una cosa por otra mejor.

DFEM: [dar u.p.] gato por liebre (inf.) Engañar en una transacción comercial: "Me han dado gato por liebre: pagué 20.000 pesetas por una pluma que no escribe".

Veamos algunos casos en los que las definiciones son perfectibles, sobre todo si las comparamos con las propuestas en el $D U E-1998$ y en el $D F E M$. Como en el DRAE no se dan los rasgos necesarios para precisar el significado de la unidad pluriverbal, resultan definiciones muy amplias o no se contemplan las diferentes acepciones que la UF puede adoptar:

22 El DRAE-2001 ha procurado minimizar al máximo los casos de definición impropia, intentando separar tipográficamente los dos enunciados. 
$D R A E-2001$ : lavar el cerebro a alguien. fr. coloq. Cambiarle la manera de pensar.

DUE-1998: LAVAR EL CEREBRO: Anular la personalidad de alguien y hacer que adopte otras convicciones y hábitos de vida, particularmente con técnicas de manipulación psicológica. $\Rightarrow{ }^{*}$ Convencer. $D F E M$ (No la registra)

$D R A E-2001$ : comer el coco a alguien. fr. coloq. Ocupar insistentemente su pensamiento con ideas ajenas, induciéndole a hacer cosas que de otro modo no haría. Ú. t. c. prnl.

DUE-1998: COMER EL COCO a alguien (inf.) Llevar a una persona a pensar algo o a actuar de cierta manera sin que exista en ella una verdadera determinación para hacerlo. $\Rightarrow$ Convencer $\triangle$ Comecocos. COMERSE alguien EL COCO (inf.) Pensar mucho sobre algo o estar obsesionado con ello. $\Rightarrow$ Comecocos.

DFEM: comerle u.p. el coco a alguien (inf.). Convencer a alguien aprovechándose de su ingenuidad o buena fe: "Ahora se dedica a comerle el coco a la gente para ganar adeptos a la nueva secta".

comerse u.p. el coco (inf.). Preocuparse: "Hace ya tiempo que no llamas a tu madre; la pobre debe estar comiéndose el coco pensando que te ha pasado algo malo".

2. En el caso de las definiciones sinonímicas, se afirma que este modelo es especialmente eficaz en el tratamiento de "la definición de variantes marcadas geográfica, técnica o cronológicamente". En estas ocasiones es habitual en el $D R A E-2001$ emplear la definición por remisión.

Esta definición por remisión no la consideramos una fórmula adecuada, salvo cuando el envío se hace dentro del mismo artículo lexicográfico (como en la entrada rosa, en la que se registra como una rosa y se remite a como las propias rosas), ya que obliga al lector a efectuar una nueva consulta. Si buscamos una UF como encogérsele a alguien el corazón, en la que sólo se contempla una de sus acepciones, tenemos que efectuar tres consultas para conseguir su definición:

DRAE-2001: encogérsele a alguien el corazón. fr. estrecharse de ánimo. estrecharse de ánimo. fr. acobardarse.

acobardar (De cobarde). tr. Amedrentar, causar o meter miedo. Ú. t.

c. prnl. y c. intr. 
En el diccionario de M. ${ }^{a}$ Moliner, este fraseologismo presenta una descripción lexicográfica más afinada, integrando los dos matices de la unidad, uno como subacepción del otro ${ }^{23}$ :

DUE-1998: ENCOGER [o ENCOGÉRSELE] EL CORAZÓN a alguien. Hacer que alguien se sienta [o sentirse] anonadado o asustado: 'De ver aquel abismo se le encoge a uno el corazón' $\odot$ Hacer sentir [o sentir] aflicción o compasión por el dolor ajeno: 'Ver a aquellas pobres criaturas encogía el corazón'.

Después de haber realizado varias consultas en el diccionario académico, creemos que el sistema de remisiones debe ser revisado y usado de forma más comedida, pues muchas de las expresiones definidas mediante envíos no consiguen una definición satisfactoria. Si bien en algunos casos es apropiado este modelo, en otros no precisa el valor de la expresión descrita, como en el siguiente ejemplo, en el que se omite información pragmática pertinente:

$D R A E-2001$ : echar una cana al aire. fr. coloq. esparcirse (\| divertirse). esparcirse. [...] 3. Divertir, desahogar, recrear. U. t. c. prnl. DUE-1998: ECHAR UNA CANA AL AIRE. Permitirse ocasionalmente una diversión o expansión alguien que de ordinario vive sin ellas.

DFEM: echar u.p. una cana al aire. (inf.) Permitirse una expansión (como excepción a la regla habitual): "A veces don Antonio, después de salir del trabajo, se va a echar una cana al aire a la cervecería".

3. Como se aclara en las Advertencias del DRAE (p. XLIX), es frecuente que la unidad que se describe no pueda ser analizada perifrástica ni sinonímicamente, situación en la que es ineludible acudir a la definición impropia. En estos casos afirma que "más que definir, contiene una explicación de la acepción de que se trata, en la que puede indicarse, entre otros aspectos, qué es, cómo se trata, para qué sirve y cómo se utiliza". Sin embargo, algunas de las expresiones o locuciones pueden ser modificadas y descritas mediante definición propia:

$D R A E-2001$ : sin decir agua va. expr. coloq. U. cuando alguien ocasiona algún daño o pesar intempestivamente y sin prevención.

23 El DFEM describe esta expresión distinguiendo dos acepciones: 'experimentar lástima o compasión por algo' y 'sentir miedo'. 
DUE-1998: SIN DECIR AGUA VA. Sin avisar. $\odot *$ Repentinamente.

DFEM (No la registra)

Otra cuestión pendiente y que se desvela cuando comparamos el análisis que cada diccionario concede a la misma UF, son las diferencias de contenido que se expresan en aquellas explicaciones que se refieren a intenciones o a estados de ánimo ${ }^{24}$.

$D R A E-2001$ : no sé que te diga. expr. coloq. U. para indicar desconfianza o incertidumbre de lo que le dicen a alguien.

DUE-1998: NO SÉ QUE TE DIGA. Expresión muy frecuente de vacilación al verse en el caso de emitir una opinión.

DFEM (No la registra)

\section{CONCLUSIONES}

De la comparación de las entradas en los distintos diccionarios generales que registran fraseología, ha quedado demostrada la utilidad que tiene cotejar la descripción de las UFS que cada uno de ellos lleva a cabo. Se debe tener siempre presente que es aconsejable y plenamente legítimo en lexicografía el uso de las obras anteriores para mejorar lo ya realizado ${ }^{25}$. Por otra parte, también los

24 Igualmente, en las UFS que se refieren a expresiones del rostro, si comparamos cómo son definidas en los diccionarios generales más importantes, comprobaremos que no coinciden en el contenido de la definición:

$D R A E-2001$ : torcer el gesto. fr. poner gesto.

poner gesto. fr. Mostrar enfado o enojo en el semblante.

DUE-1998: TORCER EL GESTO. Poner expresión de enfado o disgusto.

DFEM: torcer u.p. el gesto (f.) Expresar con el rostro descontento o desprecio.

Tampoco hay similitud en la lematización, pues sólo el DRAE registra el lema poner gesto, bajo el que incluye la definición, lo cual debería significar que esta forma es la más frecuente o la que menos restricciones presenta.

25 Una de las particularidades esenciales de los diccionarios reside en el hecho de ser obras colectivas e históricas que se nutren de la tradición lexicográfica anterior. No obstante, ya Menéndez Pidal (1945) advirtió de las consecuencias negativas de esa imitación, pues "tiene el peligro de convertirse en repetición molesta de fórmulas encerradas en la tumba de espesas columnas tipográficas”. 
trabajos teóricos de fraseología (Casares 1950, Zuluaga 1980, Corpas Pastor 1997, Ruiz Gurillo 1997, Wotjak 1998, Martínez Marín 1996, etc.) pueden contribuir a perfeccionar el análisis lexicográfico con los datos que aportan sobre las particularidades semánticas, gramaticales y pragmáticas de las UFS. A esto se pueden añadir los datos incluidos en los prólogos de los diccionarios, los trabajos publicados sobre cómo se han elaborado diccionarios de fraseología (Kubarth 1998, Ortega Ojeda y González Aguiar 2001) y la información que ocasionalmente ofrecen los manuales de lexicografía.

En cuanto a la clasificación de las definiciones lexicográficas, sería muy oportuno contar con un sistema de definiciones aplicado, en la medida de lo posible, a las diferentes UFS (Martínez Marín 2000). Además, el método de definición por envío tendría que ser examinado detenidamente.

En las próximas ediciones, el diccionario académico debería seguir apostando por aminorar el abigarramiento de expresiones que aparece en la parte del artículo lexicográfico dedicado a las formas complejas, fundamentalmente en el segundo bloque, que es el que hemos analizado. Serían deseables cambios como: la exclusión total de las expresiones sin vigencia de uso, de los fraseologismos de regiones de España, de los aparentes fraseologismos ${ }^{26}$, la lematización correcta de las expresiones (Porto 2002: 162-163), etc.

Otras cuestiones interesantes que, por falta de espacio, no hemos podido analizar son:

a) El concepto de acepción en fraseología: en el siguiente ejemplo vemos dos formas de entender el concepto de acepción: la primera más

26 Nos referimos con esta etiqueta a las combinaciones de dos o más palabras que se incluyen como UFS, pero que carecen de idiomaticidad y de fijación consolidada. Algunas de estas combinaciones podrían catalogarse como colocaciones, pues se componen en ese orden con cierto grado de frecuencia aunque sin estar plenamente arraigadas. Sobre el concepto de colocación léxica y sus distintas interpretaciones es aconsejable la consulta de Koike 2001. 
minuciosa y la segunda más integradora. En las tres acepciones que el DRAE-2001 adjudica a estar al caer está presente el valor de 'estar a punto o próximo a que suceda algo'. Tanto el $D U E-1998$ como el $D F E M$ resuelven el problema de una forma bien distinta:

$D R A E-2001$ : estar al caer. fr. coloq. estar a punto de sonar la hora que se indique. Están al caer las cinco. \| 2. estar a punto de sobrevenir o de producirse algún suceso. Estar al caer tu ascenso. || 3. estar a punto de llegar alguien.

DUE-1998: ESTAR AL ... Con un infinitivo, ser *inminente la acción expresada por este: 'Están al llegar'. $\approx$ estar para, estar a PUNTO de. DFEM: estar u.p./u.c. al caer (inf.). Estar a punto de llegar o aparecer: "Llevamos ya tres horas de viaje; París debe de estar al caer".

b) La oportunidad de ofrecer ejemplos es un aspecto importante que merece ser evaluado, pues si bien la inclusión de ejemplos es beneficiosa, con demasiada frecuencia se ofrecen ejemplos inventados o tomados exclusivamente de fuentes escritas, con lo que carecen de la naturalidad propia de los usos coloquiales espontáneos (nivel al que pertenece una parte considerable de las unidades que estamos analizando). Por otra parte, también se podría cuestionar si todas las UFS necesitan estar acompañadas de ejemplos de uso en la descripción lexicográfica.

Por último, no queremos terminar sin referirnos a las utilidades que un diccionario ideológico de fraseología del español prestaría para las cuestiones que hemos tratado, obra con la que por ahora no contamos. En el Diccionario ideológico (1942), Casares incluyó fraseología, pero su inventario fue reducido. Un registro de esta categoría se ofrecería al usuario como una obra de consulta variada y al fraseógrafo como una fuente imprescindible para conseguir fijar criterios homogéneos en la redacción de los artículos, y en especial en los problemas que atañen a la lematización y a la elaboración de las definiciones. Entre el desorden del orden alfabético y el sistema de inventariar las UFS por palabras clave, el diccionario alfabético desperdiga las voces que conceptualmente están próximas. 
En el caso de la fraseología, sector de la lengua que, como ningún otro, refleja las conexiones entre lo ontológico, lo cultural y lo lingüístico, se pondrían al descubierto numerosos enlaces y visiones culturales que distinguen a las diferentes comunidades de habla hispana. Una de las potencialidades más interesante, es que permitiría disponer de las UFS hispánicas que se emplean para referirse a diferentes conceptos, ilustrando la riqueza y diversidad del español. Así, por ejemplo, bajo el concepto 'morirse' se listarían construcciones metafóricas del tipo (tomadas del DRAE-2001):

- botar, dejar o largar, alguien el pelero (Ven.),

- cantar para el carnero (Arg. y Ur.),

- cerrar alguien el ojo,

- clavar el cacho (Ven.),

- clavar la guampa (Ur.),

- colgar las botas (Col. y Nic.),

- colgar los guantes (Col.),

- colgar los tenis (El Salv. Y Méx.)

- dar, dejar, o perder, alguien la pelleja,

- doblar alguien el petate (Méx.),

- doblar alguien el cacho (El Salv.),

- doblar la cabeza.

- entregar alguien el equipo (El Salv., Méx. y Ven.),

- entregar alguien la guardia (Ven.),
- estirar la pata,

- guindar alguien el piojo (Cuba),

- ir al tacho (Bol. y Ur.),

- irse al otro barrio,

- inse de este mundo,

- irse de viaje (Nic.),

- largar, o soltar la maleta (Chile),

- liar alguien el petate,

- pasar alguien a mejor vida.

- patear el balde (Hond.),

- pelarse alguien con la huesuda (Méx.),

- salir alguien de este mundo,

- torcer alguien la cabeza,

- torcer el pescuezo alguien,

- volar al cielo (eufem.),

- etc.

Otra utilidad sería comparar y analizar los esquemas fraseológicos con las variaciones correspondientes de cada modalidad. Además, en la labor fraseográfica permitiría actuar de forma sistemática y adoptar criterios unitarios para resolver los problemas que se plantean en torno a expresiones semejantes o muy próximas desde el punto de vista conceptual. Sirva al caso el siguiente ejemplo en el que la lematización y los modelos de definición de expresiones cognitivamente sinónimas no son uniformes: 


\begin{tabular}{|l|l|}
\multicolumn{2}{l}{} \\
\hline hasta el culo. & $\begin{array}{l}\text { loc. adj. vulg. malson. hasta las narices. } \\
\text { Está hasta el culo de que le manden. }\end{array}$ \\
\hline hasta las narices. & $\begin{array}{l}\text { loc. adj. coloq. Cansado, harto. U. t. como } \\
\text { loc. adv. }\end{array}$ \\
\hline $\begin{array}{l}\text { estar alguien hasta la punta } \\
\text { de los pelos, o del pelo. }\end{array}$ & frs. coloqs. estar hasta los pelos. \\
\hline estar alguien hasta el gorro. & fr. coloq. No aguantar más. \\
\hline estar alguien hasta la madre. & fr. coloq. malson. Méx. Estar harto. \\
\hline estar hasta el cogote. & fr. coloq. estar hasta la coronilla. \\
\hline estar alguien hasta el moño. & fr. coloq. Estar harto, no aguantar más. \\
\hline estar alguien hasta los pelos. & $\begin{array}{l}\text { fr. coloq. Estar harto o cansado de otra per- } \\
\text { sona o de algún asunto. }\end{array}$ \\
\hline estar alguien hasta el gollete. & fr. coloq. Estar cansado y harto de sufrir.|l [...] \\
\hline estar alguien hasta la coronilla. & $\begin{array}{l}\text { fr. coloq. Estar cansado y harto de sufrir al- } \\
\text { guna pretensión o exigencia. }\end{array}$ \\
\hline $\begin{array}{l}\text { hasta los cojones / los huevos / } \\
\text { las pelotas. }\end{array}$ & $\begin{array}{l}\text { [No aparecen en el } D R A E-2001, \text { pero sí se } \\
\text { recogen ejemplos en el } C R E A]\end{array}$ \\
\hline
\end{tabular}

BIBLIOGRAFÍA

\section{DICCIONARIOS}

CASARES, Julio (1942): Diccionario ideológico de la lengua española, Barcelona, Gustavo Gili. (Hemos consultado la 18. ${ }^{a}$ tirada de la segunda edición, 1992).

Hormigos García, Mariano (1998): Frases, timos y decires (que se dijeron y se dicen en los Madriles), Madrid, Ediciones La Librería.

Martínez de Sousa, José (1996): Diccionario de lexicografía práctica, Barcelona, Biblograf.

Moliner, María (1966-1967): Diccionario de uso del español (DUE), Madrid, Gredos. (Hemos consultado la segunda edición, 1998) [Citado DUE-1998]. 
Ortega Ojeda, Gonzalo y M. ${ }^{a}$ Isabel GonzÁlez Aguiar (2000): Diccionario de expresiones y refranes del español de Canarias (DEREC), Las Palmas de Gran Canaria, Cabildo Insular de Gran Canaria.

Real ACADEMia Española (200122): Diccionario de la lengua española, Madrid, Espasa. [Citado DRAE-2001]

VAREla, Fernando y Hugo KubARTH (1994): Diccionario fraseológico del español moderno, Madrid, Gredos. [Citado DFEM]

REFERENCIAS BIBLIOGRÁFICAS

BosQue, Ignacio (1982): "Sobre la teoría de la definición lexicográfica", Verba, 9, pp. 105-123.

CASARES, Julio (1950): Introducción a la lexicografía moderna, Madrid, CSIC.

Castillo Carballo, M. a Auxiliadora (2000): "Tratamiento de las unidades pluriverbales en dos diccionarios del español: $D R A E$ y $D U E$, en S. Ruhstaller y J. Prado Aragonés (eds.), Tendencias en la investigación lexicográfica del español (El diccionario como objeto de estudio lingüístico y didáctico), Huelva, Servicio de Publicaciones de la Universidad de Huelva, pp. 357-364.

CORPAs PASTOR, Gloria (1997): Manual de fraseología española, Madrid, Gredos.

(1998): "El uso de paremias en un corpus del español peninsular actual", en G. Wotjak (ed.), Estudios de fraseología y fraseografía del español actual, Madrid, Iberoamericana, pp. 365-390.

Corrales zumbado, Cristóbal (1990): "Definir "definir"”, en Actas del XX Congreso de la Sociedad Española de Lingüística, Madrid, Gredos, pp. 65-79.

Coseriu, Eugenio (1981): "Introducción al estudio estructural del léxico", en Principios de semántica estructural, Madrid, Gredos, pp. 87-142.

DÉNIZ HERnÁNDEZ, Margarita (2000): "El tratamiento de las expresiones fijas en los diccionarios modernos del español", en S. Ruhstaller y J. Prado Aragonés (eds.), Tendencias en la investigación lexicográfica del español (El diccionario como objeto de estudio lingüístico y didáctico), Huelva, Universidad de Huelva, pp. 377-386.

HAENSCH, Günther et al. (1982): La lexicografía (De la lingüística teórica a la lexicografía práctica), Madrid, Gredos. 
KoIKe, Kazumi (2001): Colocaciones léxicas en el español actual: estudio formal y léxico-semántico, Alcalá de Henares, Universidad de Alcalá-Takushoku University.

KuBARTH, Hugo (1998): "Elaboración de un diccionario fraseológico del español hablado moderno", en G. Wotjak (ed.), Estudios de fraseología y fraseografía del español actual, Madrid, Iberoamericana, pp. 323-341.

MARTÍNEZ MARÍN, Juan (1991): "Fraseología y diccionarios modernos de español", Voz y letra, II/I, pp. 117-126.

— (1996): Estudios de fraseología española, Málaga, Editorial Librería Ágora.

(2000): "El significado de las unidades fraseológicas de los diccionarios monolingües del español: el caso de las locuciones", en G. Corpas Pastor (ed.), Lenguas de Europa: estudios de fraseología, fraseografía y traducción, Granada, Comares, pp. 249-260.

Mederos, Humberto (1994): "A propósito de la definición lexicográfica", en H. Hernández (coord.), Aspectos de lexicografia contemporánea, Barcelona, Biblograf, pp. 95-106.

MENÉnDEZ PidAL, Ramón (1945): "El diccionario que deseamos", Prólogo del Diccionario General Ilustrado de la Lengua Española, Barcelona, Biblograf. [Reimpresión en 1961 con el título de "El diccionario ideal", en Estudios de lingüística, Madrid, Espasa, pp. 93-147].

Ortega OJeda, Gonzalo y M. ${ }^{a}$ Isabel GonzÁlez Aguiar (en prensa): "Pautas para la elaboración del Diccionario de expresiones y refranes del español de Canarias", en I Congreso Internacional sobre el español de Canarias, Academia Canaria de la Lengua.

Porto Dapena, José-Álvaro (2002): Manual de técnica lexicográfica, Madrid, Arco/Libros.

REY-DeBove, Josette (1967): "La definition lexicographique; bases d'une typologie formelle", Travaux de Linguistique, I, pp. 141-159.

_ (1971): Étude linguistique et semiotique des dictionnaires français contemporains, París, Mouton.

RUIz-GURILLO, Leonor (1997): Aspectos de fraseología teórica española, Valencia, Universitat de València.

(2000): "Cómo integrar la fraseología en los diccionarios monolingües", en G. Corpas Pastor (ed.), Lenguas de Europa: estudios de fraseología, fraseografía y traducción, Granada, Comares, pp. 261- 
274.

SECo, Manuel (1987): Estudios de lexicografía española, Madrid, Paraninfo.

Tristá PÉrez, Antonia M. (1998): “La fraseografía y el Diccionario de fraseología cubana”, en M. ${ }^{\mathrm{a}}$ T. Fuentes Morán y R. Werner (eds.), Lexicografías iberorrománicas: problemas, propuestas y proyectos, Madrid, Iberoamericana, pp. 169-183.

_ (1998): "La fraseología y la fraseografía", en G. Wotjak (ed.), Estudios de fraseología y fraseografía del español actual, Madrid, Iberoamericana, pp. 297-305.

WotJAK, Gerd (1998): “¿Cómo tratar las unidades fraseológicas (UF) en el diccionario?", en G. Wotjak (ed.), Estudios de fraseología y fraseografía del español actual, Madrid, Iberoamericana, pp. 307-321.

Zuluaga, Alberto (1980): Introducción al estudio de las expresiones fijas, Francfort-Berna, Peter D. Lang. 